\title{
INFLUENCE OF GLUTATHIONE ADDITION TO THE EXTENDER ON THE COOLED CAMEL SEMEN QUALITY
}

$Z_{\text {Zeidan }}$, A. E. B., A. M. El-Sharabassy', Y. A. Dowidar ${ }^{3}$, A. M. Ashour ${ }^{2}$, A. M. Amer ${ }^{1}$, E. A. A. Ahmadi ${ }^{1}$ R. M. Abou-Aianal, M. H. Farouk ${ }^{2}$ and M. H. Arafat $^{2}$

${ }^{1}$ Animal Production Research Institute, Dokki, Giza, Egypt.

${ }^{2}$ Department of Animal Production, Faculty of Agriculture, Al-Azhar University, Cairo, Egypt.

${ }^{3}$ Department of Biotechnology, Faculty of Agriculture, Al-Azhar University, Cairo, Egypt.

\section{ABSTRACT}

Semen was collected, evaluated and extended with two extenders (Lactose-yolk-citrate: LYC and Tris-yolk-fructose: TYF .The final extension rate was $1 \mathrm{ml}$ semen:4ml extender. The extended semen was divided into cervical 4 tubes added with Glutathion (GSH) at concentrations of 0.0, 0.2, 0.4 and $0.8 \mathrm{mM} / 100 \mathrm{ml}$. The extended semen was kept at $5^{\circ} \mathrm{C}$ for 5 days. After each storage time $(0,1,2,3,4$ and 5 days), the percentages of sperm motility, dead spermatozoa, abnormal spermatozoa, and acrosome damage of spermatozoa were recorded. Activities of aspartate-aminotransferase (AST) and alanine-aminotrans ferase (ALT) enzymes were recorded. The penetrating ability of camel spermatozoa added with $0.4 \mathrm{mM}$ into she-camel cervical mucus, during incubation at $37^{\circ} \mathrm{C}$ for up to 4 hours was also recorded.

The results showed that, the extended cooled camel semen with TYF extender was insignificantly higher the percentage of motile spermatozoa, while insignificantly lower the percentages of dead spermatozoa, abnormal spermatozoa and acrosome damage and leakage of AST and ALT enzymes into the extra cellular medium than LYC extender, during storage at $5^{\circ} \mathrm{C}$ for 5 days with the different concentrations of glutathione (GSH) or free - GSH medium. The advancement of storage time at $5^{\circ} \mathrm{C}$ for up to 5 days was significantly $(P<0.05)$ decreased the percentage of sperm motility, while increased significantly $((P<0.05)$ the percentages of dead spermatozoa, abnormal spermatozoa, acrosome damage and enzymatic activities(AST and ALT) with different extenders or GSH concentrations. The penetrating ability of the extended camel spermatozoa with TYF or LYC extender added with $0.4 \mathrm{mM} / 100 \mathrm{ml} \mathrm{GSH}$ into she-camel cervical mucus was significantly $(P<0.05)$ better than free-GSH medium (control), during incubation at $37^{\circ} \mathrm{C}$ for up to 4 hours. However, the advancement of incubation time at 
$37^{\circ} \mathrm{C}$ decreased significantly $(P<0.05)$ the penetration score.

\section{INTRODUCTION}

The Arabian camel (Camelusdromedarius) is an indispensable animal which contributes effectively both as a source of food and welfare to peoples living under harsh desert condition. It is frugal in habits yet highly productive of milk, meat, wool and work.

Opportunities to improve reproductive efficiency of the dromedary camel are limited by inherent characteristics, which include long gestation, a restricted breeding season and induced ovulation. The continued use of traditional management, in addition to practical difficulties in improving reproductive performance as it is often difficult to be certain that females are pregnant at the end of the breeding season. A further factor in the poor reproductive rate is the level of inbreeding in traditional herds.

Mammalian sperm cells are susceptible to lipid per oxidation by $\mathrm{O}_{2}$ and $\mathrm{H}_{2} \mathrm{O}_{2}$ because they are rich polyunsaturated fatty acids in their membrane and they lack a significant cytoplasmic component containing antioxidants which results in a decreased of sperm motility and viability (Kumar and Das, 2005). One of enzymes that are distributed in sperm cells is glutathione (GSH) which protect cell against the destructive effect of reactive oxygen species (Lewis et al., 1997). However, endogenous antioxidative capacity of semen may be insufficient during storage or dilution (Maxwell and Salamon, 1993) and addition of antioxidants as glutathione (GSH), ascorbic acid or catalase (Ahmed, 2008 and Arafat, 2015) to diluted semen which improved motility and survival rate of frozen bull and camal spermatozoa. Little literature was 
found on camel semen quality and enzymatic activates during storage at $5^{\circ} \mathrm{C}$ as affected by different extenders.

Therefore, the present study aimed to define the effect of extended cooled camel semen using Tris-yolk-fructose (TYF) or Lactose-yolkcitrate (LYC) extender added with different levels of glutathione on semen quality and enzymatic activities, during storage at $5^{\circ} \mathrm{C}$ for 5 days . The penetrating ability of spermatozoa into she-camel cervical mucus, during incubation at $37^{\circ} \mathrm{C}$ for up to 4 hours was also recorded.

\section{MATERIALS AND METHODS}

The present study was carried out in the Private Camel Farm, Belbies City, Sharkiya Governorate, Egypt, during the period from January, 2012 till August, 2013.

\section{Experimental animals:}

Fifteen male dromedary camels (Camelusdromedarius) at 5-10 years of age and 500-600 kg body live weight were used in the present experiment. The camels were in healthy condition and clinically free from external and internal parasites with a sound history of fertility in the herd. Palpation of the external genetalia showed that they were typically normal.

\section{Feeding and management:}

The rations offered to camels were calculated according to Banerjee (1988). Two types of ration were used as follows: Green season (from December to May): the average amount give per head/daily was $35 \mathrm{kgberseem} \mathrm{(Trifoliumalexandrinum)} \mathrm{and} 7 \mathrm{~kg}$ rice straw. Dry season (from June to November), each camel was received about $2 \mathrm{~kg}$ commercial concentrate mixture, $2 \mathrm{~kg}$ berseem hay and $9 \mathrm{~kg}$ rice straw daily. Clean fresh water was offered freely to all camels. Camels were 
housed in a yard which provided with common feeding through and a concrete floor provided with common sheltered water trough. The camels could more freely in enclosed area.

The present study was planned to evaluate the extended cooled camel semen quality(percentage of sperm motility, dead spermatozoa, abnormal spermatozoa and acrosom damage of spermatozoa) and enzymatic activities (aspartate-aminotransferase: AST and alanineaminotransferase: ALT) using LYC orTYF extenderadded with glutathione at concentrations of $0.0,0.2,0.4$ or $0.8 \mathrm{mM} / 100 \mathrm{ml}$, during storage at $5^{\circ} \mathrm{C}$ for 5 days. Sperm penetration into she-camel cervical mucus, during incubation at $37^{\circ} \mathrm{C}$ for up to 4 hours was also assessed.

The composition of LYC was Sodium citrate dehydrate (2.90gm), Citric acid anyhydrate $(0.04 \mathrm{gm})$, Lactose $(1.25 \mathrm{gm})$, Egg yolk (10ml), Penicillin $(500 \mathrm{IU} / \mathrm{ml})$ and Streptomycin $(500 \mu \mathrm{g} / \mathrm{ml})$, while, the composition of TYF was Citric acid anhydrate (1.675 grams), Fructose (1.25 grams), Trisaminomethan (3.208 grams), Egg yolk (10ml), Penicillin $(500 \mathrm{IU} / \mathrm{ml})$ and Streptomycin $(500 \mu \mathrm{g} / \mathrm{ml})$ for $100 \mathrm{ml}$ distilled water.

\section{Camel's semen collection using artificial vagina (AV):}

Semen was collected from the male dromedary camel between 08:00 and 10:00 am using artificial vagina (AV). A modified artificial vagina (30 $\mathrm{cm}$ long and $5 \mathrm{~cm}$ internal diameter, IMV, France) as the method described by Zeidan (2002) and Mosaferiet al. (2005). Ejaculate contact with the rubber liner of the AV was avoided, since Musa et al. (1992) recorded that most rubber liners have a deleterious effect on camel spermatozoa. An additional disposable plastic inner liner is inserted to avoid contact with the rubber material. After passing the liner 
thought the AV, $8 \mathrm{~cm}$ of cylindrical form (cut longitudinally) was placed between outer Jacket of the AV and liner at the end of the AV far from the water valve according to Bravo et al. (2000). This was performed imitate the internal cervix and provide more stimulation for the penis to stimulate of erection and natural ejaculate. A shortened AV without collection funnel was used, allowing the semen to pass directly into a collection flask. The AV was filled with warm water at $55-60^{\circ} \mathrm{C}$. The temperature inside the inner liner was stabilized at $45-50^{\circ} \mathrm{C}$. Few drops of Vaseline were smeared on the inner at the entrance of the penis to AV for provide lubrication. A sexually receptive females couching with her front legs tied and tested by the male camel should be used. The olfactory contact should be allowed. The male is left to mount the female from behind on the right side. As soon as, the male camel makes few thrusts, the operator who sits on the right side of the female grasps the males camel sheath and directs his penis into the AV. The ejaculation is completed after several thrusts and inter pressed by period usually comes in fractions. The collection flask containing the semen is protected by a towel or gauze. Immediately after semen collection, flask containing the semen was incubated in a water bath at $37^{\circ} \mathrm{C}$. Fresh camel semen that has a Jelly-like consistency was left for liquefaction for about 30-60 minutes to make the sperm motility. Immediately after collection, semen was evaluated and only ejaculates showing active wave motion $(60 \%)$ were pooled . After semen collection, it was placed inside incubator set at $37^{\circ} \mathrm{C}$ and evaluated immediately.

\subsection{Semen extension:}

Semen was collected, pooled and evaluated for each camel and then extended with LYC or TYF extender. Semen extension was carried out by adding the appropriate volume of the extender slowly to the semen. 
The final extension rate was $1 \mathrm{ml}$ semen: $4 \mathrm{ml}$ extender. Extended semen(in tube) was kept below the level of water in a water bath at $37^{\circ} \mathrm{C}$ at all times to avoid fluctuations in the temperature of the extended semen.

\subsection{Chilling of semen at $5^{\circ} \mathrm{C}$ :}

The test tubes containing extended semen were placed in a $500 \mathrm{ml}$ beaker containing water at $30^{\circ} \mathrm{C}$ with a thermometer in order to facilitate periodic checking of the temperature during the cooling period. The cooled spermatozoa were kept at $5^{\circ} \mathrm{C}$ for up to 5 days. After each storage time (0,1,2,3,4 and 5 days), the percentages of sperm motility, dead spermatozoa, abnormal spermatozoa, and acrosome damage of spermatozoa were recorded. Enzymatic activities (AST and ALT) were also recorded.

\subsection{Glutathione addition to the cooled camel semen:}

Semen samples were collected, evaluated and extended with TYF or LYC extender and cooled up to $5^{\circ} \mathrm{C}$.After each storage time $(0,1,2$, 3,4 and 5 days), the extended cooled camel semen was divided into cervical 4 tubes, and added with Glutathion (GSH) at concentrations of $0.0,0.2,0.4$ and $0.8 \mathrm{mM} / 100 \mathrm{ml}$.

\section{Procedure:}

\subsection{Camel sperm motility (\%):}

Generally, camel sperm motility (\%) was detected as an oscillatory motion the flagellum, but not progressive due to the viscous materials 
according to Tibary and Anouassi (1997). Sperm motility was estimated by adding one drop of the diluted fresh semen with physiological saline $\left(0.9 \%\right.$ sodium chloride) on the dry, clean and pre-warmed $\left(37^{\circ} \mathrm{C}\right)$ glass slide.

With regard to extended semen, the percentage of sperm motility was determined using one drop of the extended semen after each storage period for up to 5 days. The drop of the extended semen was covered by a warmed cover slip and examined immediately after liquefaction using high power magnification $(400 \mathrm{x})$.

\subsection{Dead camel spermatozoa (\%):}

The eosin/nigrosin staining procedure was carried out by dissolving $1.67 \mathrm{gm}$ eosin and $10 \mathrm{gm}$ nigrosine in distilled water up to $100 \mathrm{ml}$ according to Hackett and Macpherson (1965). The percentage of dead spermatozoa was calculated from 200 spermatozoa in each slide in the different microscopicalfields using a hand counter. Then the live spermatozoa percentage, were estimated.

\subsection{Morphological of camel spermatozoa(\%):}

The morphological abnormalites of spermatozoa (\%) were determined in the same smears prepared for live/dead spermatozoa ratio.

\subsection{Percentage of acrosome damage (\%):}

Assessment of the percentages of acrosome damage of spermatozoa (\%) were done according to Watson (1975). 
The percentages of acrosome damage of spermatozoa were calculated for 100 spermatozoa observed at random on each slide using oil immersion lens (x1000).

\subsection{Sperm-cell concentration $(\times 10 \% / \mathrm{ml})$ :}

The spermatozoa were counted using haemeocytomter according to Khan (1971).

\subsection{Transaminase enzymes ( $\mathrm{U} / 10^{6}$ spermatozoa):}

Extended semen samples were centrifuged at $1000 \mathrm{~g}$ for 15 minutes. The supernatant fluid was collected, then kept at $-20{ }^{\circ} \mathrm{C}$ until used for determination of aspartate-aminotransferase (AST) and, alanineaminotransferase (ALT). The activities of AST and ALT enzymes in seminal plasma were determined colourimetricallyusing QCA kit, Amposta, Spain according to Reitman and Frankle (1957).

\subsection{Sperm penetration score:}

Cervical mucus was obtained from she-camel during breeding season. A portion of the mucus was sucked into polyethylene sealed tubes with $2 \mathrm{~mm}$ internal diameter to provide a column of $6 \mathrm{~cm}$ length as the method described by Foote (1978) and then placed into $2 \mathrm{ml}$ cuvettes ( $1 \mathrm{ml}$ each). The tubes containing the mucus were inserted (open end) into the cuvettes containing the extended semen with TYF or LYC extenders added with $0.4 \mathrm{mM} \mathrm{GSH}$ and incubated at $37^{\circ} \mathrm{C}$ for up to 4 hours. Sperm penetration score was judged as the rank score as the method described by Eskinet al. (1973) and Hanson et al. (1982). 


\section{Statistical analysis:}

Data were statistically analyzed by Factorial design using General Linear Model (GLM) procedure of SAS (SAS, 2006) and Duncan's New Multiple Range Test (Duncan, 1955) to detect significant differences among means. The percentage values were transformed to arcsine values before being statistically analyzed.

\section{RESULTS AND DISCUSSION}

\section{Camel semen quality:}

\subsection{Motile camel spermatozoa (\%):}

Data presented in Table 1 indicated that, the percentage of sperm motility was insignificantly higher of the extended semen with TYF extender than LYC extender during storage at $5^{\circ} \mathrm{C}$ for up to 5 days. These results may be due to the combination of all beneficial effects of tris components. Tris in addition to its better buffering capacity can readily diffuse into the sperm cells and serve as an intracellular buffer (Bartlett and Van Demark, 1962). Similar trends were reported by Zeidan et al. (2014) and Matter (2018) in the dromedary camel. Vyaset al. (1998) showed that, tris extender was superior than lactose extender for camel semen preserved at $5^{\circ} \mathrm{C}$ for 48 hours.

Supplementation of the extended camel semen with glutathione $(\mathrm{GSH})$ at a level of $0.4 \mathrm{mM} / 100 \mathrm{ml}$ was a significantly $(\mathrm{P}<0.05)$ increased in the percentage of sperm motility during storage at $5{ }^{\circ} \mathrm{C}$ for 5 days with TYF extender and insignificantly higher with LYC extender. GSH addition at levels of $0.2,0.4$ and $0.8 \mathrm{mM}$ to the cooled camel semen was 
significantly $(\mathrm{P}<0.05)$ increased the percentage of sperm motility compared to free-GSH semen (control) either with TYF or LYC extender. The highest $(\mathrm{P}<0.05)$ percentage of the chilled sperm motility was recorded with the semen added with $0.4 \mathrm{mM}$ of GSH, moderate with $0.8 \mathrm{mM}$ of $\mathrm{GSH}$ and the lowest with $0.2 \mathrm{mM}$ of GSHvs. with free-GSH semen (control) eitherwith LYC or TYF extender. Similar trend was reported by Arafat (2015) in the dromedary camels.

The advancement of storage time at $5^{\circ} \mathrm{C}$ for up to 5 days was significantly $(\mathrm{P}<0.05)$ decreased the percentage of motile camel spermatozoa with two extenders (TYF or LYC) or GSH levels (0.0,0.2, 0.4 and $0.8 \mathrm{mM}$ ). Similar trends were reported by Arafat (2015) in the dromedary camel spermatozoa. This phenomenon may be attributed to the decrease in the content of adenosine triphosphate which activated spermatozoa apparently ability of resynthesizing. This was accompanied with a precipitous fall in the rate of fructolysis (Mann and LutwakMann, 1981).

Table (1): Mean percentage of motile camel spermatozoa extended with LYC or TYF extender and glutathione levels, during storage at $5{ }^{\circ} \mathrm{C}$ for up to 5 days

\begin{tabular}{|c|c|c|c|c|c|c|c|c|c|c|}
\hline \multirow{3}{*}{$\begin{array}{l}\text { Storage } \\
\text { time } \\
\text { (days) }\end{array}$} & \multirow{2}{*}{\multicolumn{4}{|c|}{$\begin{array}{c}\text { Tris-Yolk-Fructose } \\
\text { Glutathione (mMole/100ml) }\end{array}$}} & \multirow{3}{*}{ Mean } & \multicolumn{4}{|c|}{ Lactose-Yolk-Citrate } & \multirow{3}{*}{ Mean } \\
\hline & & & & & & \multicolumn{4}{|c|}{ Glutathione (mMole/100ml) } & \\
\hline & Control & 0.2 & 0.4 & 0.8 & & Control & 0.2 & 0.4 & 0.8 & \\
\hline 0 & $\begin{array}{c}65.32 \pm \\
1.15\end{array}$ & $\begin{array}{c}67.35 \pm \\
1.84\end{array}$ & $\begin{array}{c}72.52 \pm \\
1.75\end{array}$ & $\begin{array}{c}68.32 \pm \\
1.62\end{array}$ & $\begin{array}{c}68.38 \pm \\
1.52^{\mathrm{a}}\end{array}$ & $\begin{array}{c}64.51 \pm \\
1.64\end{array}$ & $\begin{array}{c}67.16 \pm \\
1.15\end{array}$ & $\begin{array}{c}70.13 \pm \\
1.18\end{array}$ & $\begin{array}{c}70.12 \pm \\
1.15\end{array}$ & $\begin{array}{c}67.98 \pm \\
1.35^{\mathrm{a}}\end{array}$ \\
\hline 1 & $\begin{array}{c}64.61 \pm \\
1.19\end{array}$ & $\begin{array}{c}65.34 \pm \\
1.52\end{array}$ & $\begin{array}{c}70.31 \pm \\
1.38\end{array}$ & $\begin{array}{c}67.25 \pm \\
1.74\end{array}$ & $\begin{array}{c}66.88 \pm \\
1.27^{\mathrm{a}}\end{array}$ & $\begin{array}{c}61.16 \pm \\
1.53\end{array}$ & $\begin{array}{c}65.19 \pm \\
1.28\end{array}$ & $\begin{array}{c}68.18 \pm \\
1.01\end{array}$ & $\begin{array}{c}67.18 \pm \\
1.28\end{array}$ & $\begin{array}{c}65.43 \pm \\
1.55^{\mathrm{a}}\end{array}$ \\
\hline 2 & $\begin{array}{c}50.62 \pm \\
1.27\end{array}$ & $\begin{array}{c}63.62 \pm \\
1.43\end{array}$ & $\begin{array}{c}67.62 \pm \\
1.25\end{array}$ & $\begin{array}{c}65.61 \pm \\
1.68\end{array}$ & $\begin{array}{c}61.87 \pm \\
1.84^{\mathrm{a}}\end{array}$ & $\begin{array}{c}52.13 \pm \\
1.72\end{array}$ & $\begin{array}{c}60.25 \pm \\
0.48\end{array}$ & $\begin{array}{c}66.22 \pm \\
1.48\end{array}$ & $\begin{array}{c}65.16 \pm \\
1.36\end{array}$ & $\begin{array}{c}60.94 \pm \\
1.21^{\mathrm{a}}\end{array}$ \\
\hline
\end{tabular}


Zeidan, A. E. B. et., al.

\begin{tabular}{|c|c|c|c|c|c|c|c|c|c|c|}
\hline 3 & $\begin{array}{c}38.32 \pm \\
1.01\end{array}$ & $\begin{array}{c}53.51 \pm \\
1.95\end{array}$ & $\begin{array}{c}60.15 \pm \\
0.81\end{array}$ & $\begin{array}{c}64.42 \pm \\
1.84\end{array}$ & $\begin{array}{c}54.10 \pm \\
1.72^{b}\end{array}$ & $\begin{array}{c}30.12 \pm \\
0.68\end{array}$ & $\begin{array}{c}46.18 \pm \\
0.74\end{array}$ & $\begin{array}{c}62.16 \pm \\
1.12\end{array}$ & $\begin{array}{c}58.24 \pm \\
1.18\end{array}$ & $\begin{array}{c}49.18 \pm \\
1.20^{\mathrm{b}}\end{array}$ \\
\hline 4 & $\begin{array}{c}26.12 \pm \\
1.08\end{array}$ & $\begin{array}{c}34.82 \pm \\
1.85\end{array}$ & $\begin{array}{c}51.62 \pm \\
0.46\end{array}$ & $\begin{array}{c}52.14 \pm \\
0.94\end{array}$ & $\begin{array}{c}41.18 \pm \\
1.43 \mathrm{c}\end{array}$ & $\begin{array}{c}24.14 \pm \\
0.64\end{array}$ & $\begin{array}{c}35.19 \pm \\
0.81\end{array}$ & $\begin{array}{c}48.15 \pm \\
0.53\end{array}$ & $\begin{array}{c}50.31 \pm \\
0.92\end{array}$ & $\begin{array}{c}39.45 \pm \\
1.09^{\mathrm{c}}\end{array}$ \\
\hline 5 & $\begin{array}{c}10.11 \pm \\
1.84\end{array}$ & $\begin{array}{c}21.15 \pm \\
0.91\end{array}$ & $\begin{array}{c}39.17 \pm \\
0.85\end{array}$ & $\begin{array}{c}31.17 \pm \\
0.42\end{array}$ & $\begin{array}{c}25.40 \pm \\
1.29^{\mathrm{d}}\end{array}$ & $\begin{array}{c}10.13 \pm \\
0.14\end{array}$ & $\begin{array}{c}19.18 \pm \\
0.13\end{array}$ & $\begin{array}{c}32.81 \pm \\
0.92\end{array}$ & $\begin{array}{c}28.48 \pm \\
0.16\end{array}$ & $\begin{array}{c}22.65 \pm \\
1.04^{\mathrm{d}}\end{array}$ \\
\hline Mean & $\begin{array}{c}42.54 \pm \\
1.24^{\mathrm{C}}\end{array}$ & $\begin{array}{c}50.97 \pm \\
1.93^{\mathrm{B}}\end{array}$ & $\begin{array}{c}60.23 \pm \\
1.31^{\mathrm{A}}\end{array}$ & $\begin{array}{c}58.16 \pm \\
1.48^{\mathrm{A}}\end{array}$ & $52.97^{\mathrm{A}}$ & $\begin{array}{c}40.37 \pm \\
1.25^{\mathrm{C}}\end{array}$ & $\begin{array}{c}48.86 \pm \\
1.94^{\mathrm{B}}\end{array}$ & $\begin{array}{c}57.94 \pm \\
1.49^{\mathrm{A}}\end{array}$ & $\begin{array}{c}56.58 \pm \\
1.58^{\mathrm{A}}\end{array}$ & $50.94^{\mathrm{A}}$ \\
\hline
\end{tabular}

A,B,C : Means with the different superscripts in the same row, differ significantly $(\mathrm{P}<0.05)$.

a,b,c,d : Means with the different superscripts in the same column, differ significantly $(\mathrm{P}<0.05)$.

\subsection{Dead camel spermatozoa (\%):}

The results obtained in Table 2 showed that, the percentage of dead spermatozoa during storage at $5^{\circ} \mathrm{C}$ was insignificantly lower with TYF than LYC extender. The lowest value of the percentage of dead spermatozoa was recorded with TYF extender, while the highest value was recorded with LYC extender. Arafat (2015) found that the lowest value of the percentage of dead spermatozoa was recorded with TYF extender and the highest value with GYC extender in the dromedary camel spermatozoa, during storage at $5^{\circ} \mathrm{C}$ for up to 5 days. Such findings may be due to the beneficial effects of TYF extender allowing more protection of spermatozoa, consequently lowering dead spermatozoa during storage at $5^{\circ} \mathrm{C}$.

Supplementation of the extended camel semen with GSH up to 0.8 $\mathrm{mM} / 100$ was significantly $(\mathrm{P}<0.05)$ decreased in the percentage of dead spermatozoa, during storage at $5^{\circ} \mathrm{C}$ 
for up to 5 days in TYF than LYC extender. GSH addition at levels of $0.2,0.4$ and $0.8 \mathrm{mM}$ showed significantly $(\mathrm{P}<0.05)$ decreased the percentage of dead spermatozoa as compared to free-GSH semen inthe different extenders (TYF or LYC). The highest $(\mathrm{P}<0.05)$ percentage of dead spermatozoa was recorded with free-semen GSH and the lowest $(\mathrm{P}<0.05)$ was recorded with the semen added with $0.4 \mathrm{mM} / 100 \mathrm{ml}$ in the different extenders (TYF or LYC). Similar trends were reported by Matter (2018) in the dromedary camel spermatozoa.

The advancement of storage time at $5^{\circ} \mathrm{C}$ for up to 5 days was significantly $(\mathrm{P}<0.05)$ increased of the percentage of dead cooled camel spermatozoa added with the all different concentrations ofGSH $(0.0,2$, 0.4 and $0.8 \mathrm{mM}$ ) or different extenders(TYF or LYC) .Similar trends were reported by Matter (2018) in the cooled camel spermatozoa. These findings may be attributed to accumulation of lactic acid which exerts a toxic effect on sperm cell and leakage of intracellular enzymes due to the increase of membrane permeability (Zeidan, 1994).

\subsection{Camel sperm morphology (\%):}

Data presented in Table 3 revealed that, the percentage of abnormal spermatozoa during storage at $5^{\circ} \mathrm{C}$ was insignificantly lower with TYF than LYC extender. The lowest value of abnormal spermatozoa was recorded with TYF and the highest value was recorded with LYC extender. Similar trend was reported by Vyas et al. (1998) who confirmed that tris extender was superior as compared to lactose extender 
in the camel semen during storage at $5^{\circ} \mathrm{C}$. These results are in agreement with those of Zeidan (2002) and Matter (2018) in the dromedary camels.

Supplementation of the extended camels semen with GSH up to 0.8 $\mathrm{mM} / 100 \mathrm{ml}$ was significantly $(\mathrm{P}<0.05)$ decreased in the percentage of abnormal spermatozoa, during storage at $5^{\circ} \mathrm{C}$ for up to 5 days either TYF or LYC extender. Glutathione addition at levels of $0.2,0.4$, and 0.8 $\mathrm{mM} / 100$ to the cooled camel semen showed significantly $(\mathrm{P}<0.05)$ decreased the percentage of abnormal spermatozoa as compared to freeGSH semen either with TYF or LYC extender. The lowest $(\mathrm{P}<0.05)$ value of abnormal spermatozoa was recorded with

Table (2): Mean percentage of dead camel spermatozoa extended with LYC or TYF extender and glutathione levels, during storage at $5^{\circ} \mathrm{C}$ for up to 5 days

\begin{tabular}{|c|c|c|c|c|c|c|c|c|c|c|}
\hline \multirow{3}{*}{$\begin{array}{c}\text { Storage } \\
\text { time } \\
\text { (days) }\end{array}$} & \multirow{2}{*}{\multicolumn{4}{|c|}{$\begin{array}{l}\text { Tris-Yolk-Fructose } \\
\text { lutathione (mMole/100ml) }\end{array}$}} & \multirow{3}{*}{ Mean } & \multirow{2}{*}{\multicolumn{4}{|c|}{$\begin{array}{l}\text { Lactose-Yolk-Citrate } \\
\text { Glutathione (mMole/100ml) }\end{array}$}} & \multirow{3}{*}{ Mean } \\
\hline & & & & & & & & & & \\
\hline & Control & 0.2 & 0.4 & 0.8 & & Control & 0.2 & 0.4 & 0.8 & \\
\hline 0 & $\begin{array}{c}19.48 \pm \\
0.94\end{array}$ & $\begin{array}{c}16.80 \pm \\
0.81\end{array}$ & $\begin{array}{c}12.10 \pm \\
0.84\end{array}$ & $\begin{array}{c}12.20 \pm \\
0.80\end{array}$ & & $\begin{array}{c}20.16 \pm \\
0.92 \\
\end{array}$ & $\begin{array}{c}17.64 \pm \\
0.92\end{array}$ & $\begin{array}{c}12.82 \pm \\
0.91\end{array}$ & $\begin{array}{c}15.18 \pm \\
0.86\end{array}$ & \\
\hline 1 & $\begin{array}{l}19.81 \pm \\
0.15\end{array}$ & $\begin{array}{c}16.86 \pm \\
0.92\end{array}$ & $\begin{array}{c}12.35 \pm \\
0.11\end{array}$ & $\begin{array}{c}12.28 \pm \\
0.91\end{array}$ & $\begin{array}{c}15.33 \pm \\
0.74^{\mathrm{d}}\end{array}$ & $\begin{array}{c}22.31 \pm \\
0.94\end{array}$ & $\begin{array}{l}17.73 \pm \\
0.98\end{array}$ & $\begin{array}{c}12.91 \pm \\
0.94\end{array}$ & $\begin{array}{c}15.24 \pm \\
0.90\end{array}$ & $\begin{array}{r}17.05 \pm \\
0.36^{\mathrm{d}}\end{array}$ \\
\hline 2 & $\begin{array}{c}27.18 \pm \\
0.16\end{array}$ & $\begin{array}{r}19.9 \\
0.2\end{array}$ & $\begin{array}{r}13.1 \\
0 .\end{array}$ & $\begin{array}{c}15.12 \pm \\
0.94\end{array}$ & $\begin{array}{r}18.8 \\
0.6\end{array}$ & $\begin{array}{c}27.18 \pm \\
1.00\end{array}$ & $\begin{array}{c}20.98 \pm \\
0.92\end{array}$ & $\begin{array}{c}15.10 \pm \\
0.91\end{array}$ & $\begin{array}{c}18.90 \pm \\
0.92\end{array}$ & $\begin{array}{r}20.54 \pm \\
0.17^{\mathrm{d}} \\
\end{array}$ \\
\hline 3 & $\begin{array}{c}36.25 \pm \\
0.98\end{array}$ & $\begin{array}{c}24.15 \pm \\
0.84\end{array}$ & $\begin{array}{c}15.29 \pm \\
0.36\end{array}$ & $\begin{array}{l}18.11 \pm \\
0.98\end{array}$ & $\begin{array}{r}23.45 \pm \\
0.81^{\mathrm{c}}\end{array}$ & $\begin{array}{c}38.25 \pm \\
0.98\end{array}$ & $\begin{array}{c}28.16 \pm \\
0.96\end{array}$ & $\begin{array}{l}17.64 \pm \\
0.26\end{array}$ & $\begin{array}{l}20.10 \pm \\
0.85\end{array}$ & $\begin{aligned} 26.04 \pm \\
0.28^{\mathrm{c}}\end{aligned}$ \\
\hline 4 & $\begin{array}{c}42.18 \pm \\
0.26\end{array}$ & $\begin{array}{c}36.17 \pm \\
0.19\end{array}$ & $\begin{array}{l}20.15 \pm \\
0.15\end{array}$ & $\begin{array}{c}22.16 \pm \\
0.16\end{array}$ & $\begin{array}{c}30.17 \pm \\
0.75^{\mathrm{b}}\end{array}$ & $\begin{array}{c}43.16 \pm \\
0.25 \\
\end{array}$ & $\begin{array}{c}37.15 \pm \\
0.41\end{array}$ & $\begin{array}{c}23.41 \pm \\
0.15\end{array}$ & $\begin{array}{c}23.11 \pm \\
0.23\end{array}$ & $\begin{array}{c}31.71 \pm \\
0.65^{\mathrm{b}}\end{array}$ \\
\hline 5 & $\begin{array}{c}49.17 \pm \\
0.92 \\
\end{array}$ & $\begin{array}{c}40.22 \pm \\
0.81\end{array}$ & $\begin{array}{c}27.23 \pm \\
0.84\end{array}$ & $\begin{array}{c}30.42 \pm \\
0.73\end{array}$ & $\begin{array}{c}36.76 \pm \\
1.00^{\mathrm{a}} \\
\end{array}$ & $\begin{array}{c}52.36 \pm \\
0.84 \\
\end{array}$ & $\begin{array}{c}43.23 \pm \\
0.81\end{array}$ & $\begin{array}{c}32.16 \pm \\
0.48\end{array}$ & $\begin{array}{c}34.81 \pm \\
0.72 \\
\end{array}$ & $\begin{array}{c}40.64 \pm \\
0.54^{\mathrm{a}} \\
\end{array}$ \\
\hline Mean & $\begin{array}{c}32.35 \pm \\
1.24^{\mathrm{A}} \\
\end{array}$ & $\begin{array}{c}25.69 \pm \\
1.03^{\mathrm{B}} \\
\end{array}$ & $\begin{array}{c}16.71 \pm \\
0.61^{\mathrm{C}} \\
\end{array}$ & $\begin{array}{c}18.38 \pm \\
0.71^{\mathrm{C}} \\
\end{array}$ & $23.28^{\mathrm{A}}$ & $\begin{array}{c}33.90 \pm \\
1.30^{\mathrm{A}} \\
\end{array}$ & $\begin{array}{c}27.48 \pm \\
1.09^{\mathrm{B}} \\
\end{array}$ & $\begin{array}{c}19.01 \pm \\
0.77^{\mathrm{C}} \\
\end{array}$ & $\begin{array}{c}21.22 \pm \\
0.74^{\mathrm{C}} \\
\end{array}$ & $25.40^{-2}$ \\
\hline
\end{tabular}

A,B,C : Means with the different superscripts in the same row, differ significantly $(\mathrm{P}<0.05)$. a,b,c,d,e : Means with the different superscripts in the same column, differ significantly $(\mathrm{P}<0.05)$. 
Table (3): Mean percentage of abnormal spermatozoa of the extended camel semen with LYC or TY extender and glutathione levels, during storage at $5^{\circ} \mathrm{C}$ for up to 5 days

\begin{tabular}{|c|c|c|c|c|c|c|c|c|c|c|}
\hline \multirow{3}{*}{$\begin{array}{c}\text { Storage time } \\
\text { (days) }\end{array}$} & \multirow{2}{*}{\multicolumn{4}{|c|}{$\begin{array}{c}\text { Tris-Yolk-Fructose } \\
\text { Glutathione (mMole/100ml) }\end{array}$}} & \multirow{3}{*}{ Mean } & \multirow{2}{*}{\multicolumn{4}{|c|}{$\begin{array}{c}\text { Lactose-Yolk-Citrate } \\
\text { Glutathione (mMole } / 100 \mathrm{ml})\end{array}$}} & \multirow{3}{*}{ Mean } \\
\hline & & & & & & & & & & \\
\hline & Control & 0.2 & 0.4 & 0.8 & & Control & 0.2 & 0.4 & 0.8 & \\
\hline 0 & \begin{tabular}{|c|}
$10.12 \pm$ \\
0.74 \\
\end{tabular} & $\begin{array}{l}7.11 \pm \\
0.65\end{array}$ & $\begin{array}{c}4.16 \pm \\
0.16\end{array}$ & $\begin{array}{c}5.18 \pm \\
0.16 \\
\end{array}$ & $\begin{array}{l}6.64 \pm \\
0.05^{\mathrm{d}}\end{array}$ & $\begin{array}{c}10.46 \pm \\
0.13 \\
\end{array}$ & $\begin{array}{c}8.11 \pm \\
0.10\end{array}$ & $\begin{array}{c}4.28 \pm \\
0.15\end{array}$ & $\begin{array}{c}5.06 \pm \\
0.08\end{array}$ & $\begin{array}{l}6.98 \pm \\
0.08 \mathrm{de}\end{array}$ \\
\hline 1 & \begin{tabular}{|c|}
$10.47 \pm$ \\
0.80 \\
\end{tabular} & $\begin{array}{c}8.19 \pm \\
0.32\end{array}$ & $\begin{array}{c}4.28 \pm \\
0.18\end{array}$ & $\begin{array}{c}5.43 \pm \\
0.18\end{array}$ & $\begin{array}{l}7.09 \pm \\
0.06^{\mathrm{d}}\end{array}$ & $\begin{array}{c}10.81 \pm \\
0.17 \\
\end{array}$ & $\begin{array}{c}8.20 \pm \\
0.18\end{array}$ & $\begin{array}{c}5.11 \pm \\
0.16\end{array}$ & $\begin{array}{c}6.01 \pm \\
0.10\end{array}$ & $\begin{array}{l}7.53 \pm \\
0.07^{\mathrm{d}}\end{array}$ \\
\hline 2 & $\begin{array}{c}16.35 \pm \\
0.92\end{array}$ & $\begin{array}{c}10.12 \pm \\
0.28\end{array}$ & $\begin{array}{c}6.05 \pm \\
0.18\end{array}$ & $\begin{array}{c}6.14 \pm \\
0.20\end{array}$ & $\begin{array}{l}9.67 \pm \\
0.18^{d}\end{array}$ & $\begin{array}{c}16.38 \pm \\
0.19\end{array}$ & $\begin{array}{l}12.11 \pm \\
0.16\end{array}$ & $\begin{array}{c}6.28 \pm \\
0.16\end{array}$ & $\begin{array}{c}7.12 \pm \\
0.12\end{array}$ & $\begin{array}{r}10.47 \pm \\
0.08^{\mathrm{d}}\end{array}$ \\
\hline 3 & \begin{tabular}{|c|}
$27.16 \pm$ \\
0.94 \\
\end{tabular} & $\begin{array}{c}14.28 \pm \\
0.29\end{array}$ & $\begin{array}{l}10.13 \pm \\
0.25\end{array}$ & $\begin{array}{l}10.15 \pm \\
0.25\end{array}$ & $\begin{array}{c}15.43 \pm \\
0.15^{\mathrm{c}}\end{array}$ & $\begin{array}{c}28.17 \pm \\
0.22 \\
\end{array}$ & $\begin{array}{c}16.30 \pm \\
0.14\end{array}$ & $\begin{array}{c}12.15 \pm \\
0.18\end{array}$ & $\begin{array}{l}12.36 \pm \\
0.13\end{array}$ & $\begin{array}{r}17.25 \pm \\
0.13^{\mathrm{c}} \\
\end{array}$ \\
\hline 4 & \begin{tabular}{|c|}
$33.28 \pm$ \\
0.10 \\
\end{tabular} & $\begin{array}{c}19.16 \pm \\
0.34\end{array}$ & $\begin{array}{c}12.18 \pm \\
0.30\end{array}$ & $\begin{array}{c}12.45 \pm \\
0.28 \\
\end{array}$ & $\begin{array}{c}19.27 \pm \\
0.43^{\mathrm{b}} \\
\end{array}$ & \begin{tabular}{|c|}
$35.02 \pm$ \\
0.25 \\
\end{tabular} & $\begin{array}{c}18.26 \pm \\
0.19 \\
\end{array}$ & $\begin{array}{c}14.10 \pm \\
0.18 \\
\end{array}$ & $\begin{array}{c}15.01 \pm \\
0.18 \\
\end{array}$ & $\begin{array}{c}20.61 \pm \\
0.12^{\mathrm{b}} \\
\end{array}$ \\
\hline 5 & \begin{tabular}{|c|}
$40.02 \pm$ \\
0.22 \\
\end{tabular} & $\begin{array}{c}26.14 \pm \\
0.91\end{array}$ & $\begin{array}{c}15.74 \pm \\
0.72\end{array}$ & $\begin{array}{c}16.11 \pm \\
0.81\end{array}$ & $\begin{array}{c}24.50 \pm \\
0.38^{\mathrm{a}}\end{array}$ & \begin{tabular}{|c|}
$40.16 \pm$ \\
0.74 \\
\end{tabular} & $\begin{array}{c}24.15 \pm \\
0.81\end{array}$ & $\begin{array}{c}19.50 \pm \\
0.21\end{array}$ & $\begin{array}{c}20.04 \pm \\
0.85\end{array}$ & $\begin{array}{c}25.96 \pm \\
0.82^{\mathrm{a}} \\
\end{array}$ \\
\hline Mean & \begin{tabular}{|c|}
$22.90 \pm$ \\
$1.27^{\mathrm{A}}$
\end{tabular} & $\begin{array}{c}14.17 \pm \\
0.75^{\mathrm{B}}\end{array}$ & $\begin{array}{c}8.76 \pm \\
0.48^{\mathrm{C}}\end{array}$ & $\begin{array}{c}9.24 \pm \\
0.45^{\mathrm{C}}\end{array}$ & $13.76^{\mathrm{A}}$ & \begin{tabular}{|c|}
$23.50 \pm$ \\
$1.30^{\mathrm{A}}$
\end{tabular} & $\begin{array}{c}14.52 \pm \\
0.64^{\mathrm{B}}\end{array}$ & $\begin{array}{c}10.24 \pm \\
0.61^{\mathrm{C}}\end{array}$ & $\begin{array}{c}10.39 \pm \\
0.60^{\mathrm{C}}\end{array}$ & $14.80^{\mathrm{A}}$ \\
\hline
\end{tabular}

A,B,C : Means with the different superscripts in the same row, differ significantly $(\mathrm{P}<0.05)$.

a,b,c,d,e : Means with the different superscripts in the same column, differ significantly $(\mathrm{P}<0.05)$.

$0.4 \mathrm{mM}$ GSH and the highest $(\mathrm{P}<0.05)$ value was observed with free- GSH semen. Similar trend was reported by Zeidan et al. (2014) in the dromedary camel spermatozoa.

The prolongation of storage at $5^{\circ} \mathrm{C}$ for 5 days increased significantly $(\mathrm{P}<0.05)$ the percentage of abnormal camel spermatozoa in the different extenders (TYF or LYC) or GSH levels (0,0,0.2, 0.4 and 0.8 $\mathrm{mM})$. The lowest $(\mathrm{P}<0.05)$ value of abnormal spermatozoa was recoded at zero times, while the highest value $(\mathrm{P}<0.05)$ was recorded at fifth day with two extenders (TYF or LYC). These results might be attributed to the better protection of tris or lactose-yolk-citrate extenders to spermatozoa against osmotic shock, during refrigeration at $5{ }^{\circ} \mathrm{C}$. Similar trend was reported by Zeidan (2002) and Matter (2018) on the cooled camel's spermatozoa. 


\subsection{Acrosome damage (\%):}

Data presented in Table4 indicated that, the effect of extenders (TYF or LYC) on the percentage of the acrosome damage of the cooled camel spermatozoa was insignificant. The percentage of the acrosome damage of spermatozoa was insignificantly minimum with storage of semen at $5{ }^{\circ} \mathrm{C}$ in TYF extender, whereas reached insignificantly maximum with LYC extender. Similar trend was reported by Maiada (2011) and Matter (2018) in the dromedary camels. Zeidan et al. (2014) in the dromedary camel found also that the lowest $(\mathrm{P}<0.01)$ value ofacrosome damage of the camel spermatozoa was recorded with LYC extender and the highest $(\mathrm{P}<0.01)$ value with glucose-yolk-citrate $\mathrm{GYC}$ extender, during storage at $5^{\circ} \mathrm{C}$ fo 4 days.

Supplementation of the extended camel semen with GSH up to $0.8 \mathrm{mM} / 100 \mathrm{ml}$ caused a significantly $(\mathrm{P}<0.05)$ decreased the percentage of damaged acrosome during storage at $5^{\circ} \mathrm{C}$ for up to 5 days with TYF or LYC extender. The highest $(\mathrm{P}<0.05)$ value of the percentage of the acrosome damage was recorded with free-GSH semen and the lowest $(\mathrm{P}<0.05)$ value was observed with the extended semen added with $0.4 \mathrm{mM}$ GSH either in TYF or LYC extender. Similar trend was reported by Matter (2018) in the dromedary camel semen.

The prolongation of storage at $5{ }^{\circ} \mathrm{C}$ for up to 5 days was significantly $(\mathrm{P}<0.05)$ higher at the percentage of acrosome damage of the dromedary camel spermatozoa either TYF or LYC extender or different levels of GSH $(0.0,0.2,0.4$ and $0.8 \mathrm{mM})$. The highest value of acrosome damage was recorded at fifth day, while the lowest $(\mathrm{P}<0.05)$ value was recorded at zero time with different extenders (TYF or LYC). 
These results are in agreement with those of Zeidan et al. (2014) and Matter (2018) in the dromedary camel.

\section{Enzymatic activity (U/I0 ${ }^{6}$ spermatozoa):}

Data presented in Tables 5 and 6 showed that the amounts of AST and ALT enzymes released into the extra cellular medium in the camel semen were insignificantly lower in the

extended semen with TYF than LYC extender. These results may be due to that the camel semen extended with TYF extender showed the highest sperm motility, as well as, the lowest of acrosome damage which was associated with the lowest AST and ALT enzymes activity (Rasul et al., 2000). These findings may be attributed to the protective mechanism of the beneficial components of tris extender to sperm-cell membrane against any changes in the

Table (4): Mean percentage of the acrosome damage of the extended camel spermatozoa with LYC or TYF extender and glutathione levels, during storage at $5^{\circ} \mathrm{C}$ for up to 5 days

\begin{tabular}{|c|c|c|c|c|c|c|c|c|c|c|}
\hline \multirow{3}{*}{$\begin{array}{c}\text { Storage } \\
\text { time } \\
\text { (days) }\end{array}$} & \multicolumn{4}{|c|}{ Tris-Yolk-Fructose } & \multirow{3}{*}{ Mean } & \multicolumn{4}{|c|}{ Lactose-Yolk-Citrate } & \multirow{3}{*}{ Mean } \\
\hline & \multicolumn{4}{|c|}{ Glutathione (mMole/100ml) } & & \multicolumn{4}{|c|}{ Glutathione (mMole/100ml) } & \\
\hline & Control & 0.2 & 0.4 & 0.8 & & Control & 0.2 & 0.4 & 0.8 & \\
\hline 0 & $\begin{array}{c}6.15 \pm \\
0.10\end{array}$ & $\begin{array}{c}2.28 \pm \\
0.06\end{array}$ & $\begin{array}{c}1.18 \pm \\
0.02\end{array}$ & $\begin{array}{c}1.35 \pm \\
0.02\end{array}$ & $\begin{array}{l}2.74 \pm \\
0.04^{\mathrm{abc}}\end{array}$ & $\begin{array}{c}6.18 \pm \\
0.08\end{array}$ & $\begin{array}{c}2.34 \pm \\
0.06\end{array}$ & $\begin{array}{c}1.27 \pm \\
0.02\end{array}$ & $\begin{array}{c}1.82 \pm \\
0.02\end{array}$ & $\begin{array}{l}2.90 \pm \\
0.13^{\mathrm{e}}\end{array}$ \\
\hline 1 & $\begin{array}{c}6.28 \pm \\
0.12\end{array}$ & $\begin{array}{c}3.15 \pm \\
0.07\end{array}$ & $\begin{array}{c}2.03 \pm \\
0.06\end{array}$ & $\begin{array}{c}2.47 \pm \\
0.03\end{array}$ & $\begin{array}{l}3.48 \pm \\
0.03^{\mathrm{ab}}\end{array}$ & $\begin{array}{c}7.37 \pm \\
0.07\end{array}$ & $\begin{array}{c}3.26 \pm \\
0.02\end{array}$ & $\begin{array}{c}2.15 \pm \\
0.04\end{array}$ & $\begin{array}{c}2.51 \pm \\
0.01\end{array}$ & $\begin{array}{l}3.82 \pm \\
0.12^{\mathrm{d}}\end{array}$ \\
\hline 2 & $\begin{array}{c}8.17 \pm \\
0.14\end{array}$ & $\begin{array}{c}5.16 \pm \\
0.02\end{array}$ & $\begin{array}{c}2.41 \pm \\
0.06\end{array}$ & $\begin{array}{c}2.64 \pm \\
0.03\end{array}$ & $\begin{array}{l}4.60 \pm \\
0.05^{\mathrm{ab}}\end{array}$ & $\begin{array}{c}8.25 \pm \\
0.08\end{array}$ & $\begin{array}{c}5.46 \pm \\
0.05\end{array}$ & $\begin{array}{c}3.12 \pm \\
0.06\end{array}$ & $\begin{array}{c}2.18 \pm \\
0.04\end{array}$ & $\begin{array}{l}4.75 \pm \\
0.16^{\mathrm{de}}\end{array}$ \\
\hline
\end{tabular}




\begin{tabular}{|c|c|c|c|c|c|c|c|c|c|c|}
\hline 3 & $\begin{array}{c}10.25 \pm \\
0.16\end{array}$ & $\begin{array}{c}6.26 \pm \\
0.06\end{array}$ & $\begin{array}{c}3.11 \pm \\
0.08\end{array}$ & $\begin{array}{c}4.18 \pm \\
0.04\end{array}$ & $\begin{array}{l}5.95 \pm \\
0.04^{\mathrm{ab}}\end{array}$ & $\begin{array}{c}11.16 \pm \\
0.10\end{array}$ & $\begin{array}{c}7.18 \pm \\
0.06\end{array}$ & $\begin{array}{c}4.11 \pm \\
0.08\end{array}$ & $\begin{array}{c}4.16 \pm \\
0.03\end{array}$ & $\begin{array}{c}6.65 \pm \\
0.17^{c}\end{array}$ \\
\hline 4 & $\begin{array}{c}14.17 \pm \\
0.16\end{array}$ & $\begin{array}{c}9.13 \pm \\
0.09\end{array}$ & $\begin{array}{c}4.10 \pm \\
0.90\end{array}$ & $\begin{array}{c}5.15 \pm \\
0.06\end{array}$ & $\begin{array}{l}8.14 \pm \\
0.12^{\text {ab }}\end{array}$ & $\begin{array}{c}15.28 \pm \\
0.12\end{array}$ & $\begin{array}{c}10.12 \pm \\
0.08\end{array}$ & $\begin{array}{c}5.02 \pm \\
0.03\end{array}$ & $\begin{array}{c}5.24 \pm \\
0.05\end{array}$ & $\begin{array}{c}8.92 \pm \\
0.28^{b}\end{array}$ \\
\hline 5 & $\begin{array}{c}18.40 \pm \\
0.18\end{array}$ & $\begin{array}{c}12.18 \pm \\
0.08\end{array}$ & $\begin{array}{c}6.48 \pm \\
0.09\end{array}$ & $\begin{array}{c}8.10 \pm \\
0.06\end{array}$ & $\begin{array}{c}11.29 \pm \\
0.10^{\mathrm{a}}\end{array}$ & $\begin{array}{c}20.17 \pm \\
0.18\end{array}$ & $\begin{array}{c}14.15 \pm \\
0.11\end{array}$ & $\begin{array}{c}8.10 \pm \\
0.07\end{array}$ & $\begin{array}{c}8.15 \pm \\
0.09\end{array}$ & $\begin{array}{c}12.64 \pm \\
0.16^{\mathrm{a}}\end{array}$ \\
\hline Mean & $\begin{array}{c}10.57 \pm \\
0.49^{\mathrm{A}}\end{array}$ & $\begin{array}{l}6.36 \pm \\
0.38^{\mathrm{B}}\end{array}$ & $\begin{array}{l}3.22 \pm \\
0.19^{\mathrm{C}}\end{array}$ & $\begin{array}{l}3.98 \pm \\
0.25^{\mathrm{C}}\end{array}$ & $6.03^{\mathrm{A}}$ & $\begin{array}{c}11.40 \pm \\
0.55^{\mathrm{A}}\end{array}$ & $\begin{array}{l}7.09 \pm \\
0.45^{\mathrm{B}}\end{array}$ & $\begin{array}{l}3.96 \pm \\
0.25^{\mathrm{C}}\end{array}$ & $\begin{array}{l}4.01 \pm \\
0.24^{\mathrm{C}}\end{array}$ & $6.61^{\mathrm{A}}$ \\
\hline
\end{tabular}

A,B,C : Means with the different superscripts in the same row, differ significantly $(\mathrm{P}<0.05)$.

a,b,c,d,e : Means with the different superscripts in the same column, differ significantly $(\mathrm{P}<0.05)$.

plasma membrane, consequently lowering the amount of enzymes leakage from the intracellular to extracellular medium. Similar trends were reported by Zeidanet al. (2008) and Matter (2018) in the dromedary camel spermatozoa.

The results revealed that supplementation of GSH at concentrations of $0.2,0.4$ and $0.8 \mathrm{mM}$ to the cooled camel semen showed significantly $(\mathrm{P}<0.05)$ reduced. The amount of AST and ALT enzymes released into the extra cellular medium showed significantly $(\mathrm{P}<0.05)$ lower with compared to free-GSH medium. Among GSH levels, the lowest $(\mathrm{P}<0.05)$ amounts of AST and ALT enzymes in camel semen was recorded with 0.4 and $0.8 \mathrm{mM} / 100 \mathrm{ml}$ and the highest $(\mathrm{P}<0.05)$ amounts with free-GSH medium. Such findings indicated beneficial effects of GSH addition at concentrations of $0.2,0.4$ and $0.8 \mathrm{mM}$ on membrane integrity of spermatozoa with compared to free-GSH medium (control). Similar trends were obtained by Matter (2018), in the dromedarycamel. 
Moreover, the observed improvement with all GSH levels may be attributed to the protective mechanism of GSH to the spermatozoal cell against the destructive effect of reactive oxygen species (Lewis et al., 1997). Similar trends were reported by Matter (2018) in the dromedarycamel semen they reported that the addition of antioxidant (GSH) to extended frozen-thawed semen improved spermatozoal quality, being the best with $0.4 \mathrm{mM}$ concentration.

The advancement of storage at $5^{\circ} \mathrm{C}$ for up to 5 days increased significantly $(\mathrm{P}<0.05)$ the activity of AST and ALT enzymes in camel semen supplemented with different concentrations of GSH $(0.2,0.4$ and $0.8 \mathrm{mM}$ ) or free-GSH medium with the different extenders (TYF or LYC). It is of interest to note that, GSH supplementation at concentrations of 0.4 or $0.8 \mathrm{mM}$ to the extended camel semen showed the lowest AST and ALT enzymes activity at different storage times. The lowest amount of AST and ALT enzymes released into the extra cellular medium may be attributed the beneficial effects of GSH on semen quality in trends of less spermatozoal cell injury and less membrane damage of spermatozoa (Rasulet al., 2000). These results are in agreement with those reported by Zeidanet al. (2008) and Matter (2018) in the dromedary camel spermatozoa. It appears that spermatozoa damage during storage may be associated with leakage of intracellular enzymes and increased membrane permeability.

\section{Sperm penetration into she-camel cervical mucus:}


The mean penetrating ability of the camel spermatozoa into shecamel cervical mucus was significantly $(\mathrm{P}<0.05)$ better with the extended semen in TYF than LYC extender (Figure 1) during incubation at $37{ }^{\circ} \mathrm{C}$ for 4 hours. However, the advancement of incubation time at $37^{\circ} \mathrm{C}$ for up to 4 hours decreased significantly $(\mathrm{P}<0.05)$ the penetrating ability of spermatozoa into she-camel cervical mucus either TYF or LYC extender with $0.4 \mathrm{mM}$ GSH or free GSH-medium (control). Aitken et al. (1983) found a close correlation between human spermatozoa movement and their penetrating ability into cervical mucus. Muraseet al. (1990) reported that, the duration of sperm motility and penetration distance in the mucus was closely correlated to the pregnancy and conceptionrate. Similar findings were recorded by Zeidan (2002), Maiada (2011) and Matter (2018) in the dromedary camel spermatozoa.

Table (5): Activity of aspartate-aminotransferase enzyme (U/10 ${ }^{6}$ spermatozoa) in the extended camel semen with LYC or TYF extender as affected by glutathione levels, during storage at $5^{\circ} \mathrm{C}$ for up to 5 days

\begin{tabular}{|c|c|c|c|c|c|c|c|c|c|c|}
\hline \multirow{3}{*}{$\begin{array}{c}\text { Storage } \\
\text { time } \\
\text { (days) }\end{array}$} & \multirow{2}{*}{\multicolumn{4}{|c|}{$\begin{array}{l}\text { Tris-Yolk-Fructose } \\
\text { utathione }(\mathrm{mMole} / 100 \mathrm{ml})\end{array}$}} & \multirow{3}{*}{ Mean } & \multirow{2}{*}{\multicolumn{4}{|c|}{$\begin{array}{c}\text { Lactose-Yolk-Citrate } \\
\text { Glutathione (mMole/100ml) }\end{array}$}} & \multirow{3}{*}{ Mean } \\
\hline & & & & & & & & & & \\
\hline & Control & 0.2 & 0.4 & 0.8 & & Control & 0.2 & 0.4 & 0.8 & \\
\hline 0 & $\begin{array}{l}27.21 \pm \\
0.53\end{array}$ & $\begin{array}{l}20.13 \pm \\
0.42\end{array}$ & $\begin{array}{l}18.64 \pm \\
0.08\end{array}$ & $\begin{array}{l}18.71 \pm \\
0.08\end{array}$ & $\begin{array}{r}21.17 \pm \\
0.84^{\mathrm{f}}\end{array}$ & $\begin{array}{c}30.85 \pm \\
0.81\end{array}$ & $\begin{array}{c}26.14 \pm \\
0.14\end{array}$ & $\begin{array}{l}18.71 \pm \\
0.16\end{array}$ & $\begin{array}{c}20.13 \pm \\
0.07\end{array}$ & $\begin{array}{r}23.96 \pm \\
0.85^{\mathrm{f}}\end{array}$ \\
\hline 1 & $\begin{array}{c}34.35 \pm \\
0.81 \\
\end{array}$ & $\begin{array}{c}24.25 \pm \\
0.16 \\
\end{array}$ & $\begin{array}{c}20.35 \pm \\
0.32 \\
\end{array}$ & $\begin{array}{c}22.25 \pm \\
0.18\end{array}$ & \begin{tabular}{|c|}
$25.30 \pm$ \\
$0.91^{\mathrm{e}}$ \\
\end{tabular} & $\begin{array}{c}37.18 \pm \\
0.74 \\
\end{array}$ & $\begin{array}{c}28.11 \pm \\
0.13 \\
\end{array}$ & $\begin{array}{c}20.16 \pm \\
0.18\end{array}$ & $\begin{array}{c}25.14 \pm \\
0.18 \\
\end{array}$ & $\begin{array}{r}27.65 \pm \\
0.91^{\mathrm{e}} \\
\end{array}$ \\
\hline 2 & $\begin{aligned} 41.6 \\
1.6\end{aligned}$ & $\begin{array}{r}36 . \\
0 .\end{array}$ & $\begin{array}{r}23.2 \\
0 .\end{array}$ & $\begin{array}{c}26.32 \pm \\
0.36\end{array}$ & \begin{tabular}{|c|}
$31.90 \pm$ \\
$1.06^{\mathrm{d}}$ \\
\end{tabular} & $\begin{array}{c}46.73 \pm \\
0.68\end{array}$ & $\begin{array}{r}32.1 \\
0.8\end{array}$ & $\begin{array}{c}30.18 \pm \\
0.19\end{array}$ & $\begin{array}{c}34.19 \pm \\
0.60\end{array}$ & $\begin{array}{l}35.81 \pm \\
0.96^{\mathrm{d}}\end{array}$ \\
\hline 3 & $\begin{array}{l}53.81 \pm \\
1.10\end{array}$ & $\begin{array}{c}47.35 \pm \\
0.84\end{array}$ & $\begin{array}{c}38.18 \pm \\
0.42\end{array}$ & $\begin{array}{c}29.85 \pm \\
0.84\end{array}$ & \begin{tabular}{|c|}
$42.30 \pm$ \\
$1.03^{\mathrm{c}}$
\end{tabular} & $\begin{array}{c}60.17 \pm \\
1.11\end{array}$ & $\begin{array}{l}46.15 \pm \\
0.96\end{array}$ & $\begin{array}{c}42.16 \pm \\
0.84\end{array}$ & $\begin{array}{l}42.10 \pm \\
0.76\end{array}$ & $\begin{array}{l}47.65 \pm \\
1.02^{\mathrm{c}}\end{array}$ \\
\hline 4 & $\begin{array}{c}64.75 \pm \\
1.48 \\
\end{array}$ & $\begin{array}{c}56.24 \pm \\
1.16 \\
\end{array}$ & $\begin{array}{l}48.74 \pm \\
1.15 \\
\end{array}$ & $\begin{array}{l}50.73 \pm \\
0.65\end{array}$ & \begin{tabular}{|c|}
$55.12 \pm$ \\
$1.07^{\mathrm{b}}$ \\
\end{tabular} & $\begin{array}{c}68.16 \pm \\
1.13 \\
\end{array}$ & $\begin{array}{c}55.18 \pm \\
1.16 \\
\end{array}$ & $\begin{array}{c}50.61 \pm \\
1.08 \\
\end{array}$ & $\begin{array}{c}51.50 \pm \\
1.06 \\
\end{array}$ & $\begin{array}{c}56.36 \pm \\
1.00^{\mathrm{b}} \\
\end{array}$ \\
\hline 5 & $\begin{array}{c}78.64 \pm \\
1.72 \\
\end{array}$ & $\begin{array}{c}65.73 \pm \\
1.37\end{array}$ & $\begin{array}{c}56.11 \pm \\
1.48\end{array}$ & $\begin{array}{c}58.84 \pm \\
1.17\end{array}$ & \begin{tabular}{|c|}
$64.83 \pm$ \\
$1.12^{\mathrm{a}}$ \\
\end{tabular} & $\begin{array}{c}78.91 \pm \\
1.62\end{array}$ & $\begin{array}{c}68.12 \pm \\
1.54\end{array}$ & $\begin{array}{c}56.70 \pm \\
1.42\end{array}$ & $\begin{array}{c}60.11 \pm \\
1.15\end{array}$ & $\begin{array}{c}65.96 \pm \\
1.13^{\mathrm{a}} \\
\end{array}$ \\
\hline Mean & $\begin{array}{c}50.07 \pm \\
1.15^{\mathrm{A}} \\
\end{array}$ & $\begin{array}{c}41.69 \pm \\
1.13^{\mathrm{B}} \\
\end{array}$ & $\begin{array}{c}34.21 \pm \\
0.86^{\mathrm{C}}\end{array}$ & $\begin{array}{c}34.45 \pm \\
1.06^{\mathrm{C}} \\
\end{array}$ & $40.10^{\mathrm{A}}$ & $\begin{array}{c}53.67 \pm \\
1.08^{\mathrm{A}} \\
\end{array}$ & $\begin{array}{c}22.64 \pm \\
0.94^{\mathrm{B}} \\
\end{array}$ & $\begin{array}{c}36.42 \pm \\
0.91^{\mathrm{C}}\end{array}$ & $\begin{array}{c}38.86 \pm \\
1.10^{\mathrm{C}} \\
\end{array}$ & $42.90^{\mathrm{A}}$ \\
\hline
\end{tabular}

A,B,C : Means with the different superscripts in the same row, differ significantly $(\mathrm{P}<0.05)$. 
Table (6): Activity of alanine-aminotransferase enzyme (U/10 $0^{6}$ spermatozoa) in the extended camel semen with LYC or TYF extender as affected by glutathione levels, during storage at $5{ }^{\circ} \mathrm{C}$ for up to 5 days

\begin{tabular}{|c|c|c|c|c|c|c|c|c|c|c|}
\hline \multirow{3}{*}{$\begin{array}{l}\text { Storage } \\
\text { time } \\
\text { (days) }\end{array}$} & \multirow{2}{*}{\multicolumn{4}{|c|}{$\begin{array}{l}\text { Tris-Yolk-Fructose } \\
\text { tathione (mMole/100ml) }\end{array}$}} & \multirow{3}{*}{ Mean } & \multirow{2}{*}{\multicolumn{4}{|c|}{$\begin{array}{c}\text { Lactose-Yolk-Citrate } \\
\text { Glutathione (mMole/100ml) }\end{array}$}} & \multirow{3}{*}{ Mean } \\
\hline & & & & & & & & & & \\
\hline & Control & 0.2 & 0.4 & 0.8 & & Control & 0.2 & 0.4 & 0.8 & \\
\hline 0 & $\begin{array}{c}52.27 \pm \\
1.11\end{array}$ & $\begin{array}{c}38.16 \pm \\
0.72\end{array}$ & $\begin{array}{c}26.13 \pm \\
0.68\end{array}$ & $\begin{array}{c}26.85 \pm \\
0.43\end{array}$ & $\begin{array}{c}35.85 \pm \\
0.73^{\mathrm{e}}\end{array}$ & $\begin{array}{l}56.22 \pm \\
0.78\end{array}$ & $\begin{array}{c}40.12 \pm \\
0.84\end{array}$ & $\begin{array}{c}27.15 \pm \\
0.84\end{array}$ & $\begin{array}{l}30.11 \pm \\
0.65\end{array}$ & $\begin{array}{c}38.40 \pm \\
0.64^{\mathrm{e}}\end{array}$ \\
\hline 1 & $\begin{array}{c}52.18 \pm \\
1.04\end{array}$ & $\begin{array}{c}40.81 \pm \\
0.70\end{array}$ & $\begin{array}{c}28.71 \pm \\
0.72\end{array}$ & $\begin{array}{l}28.72 \pm \\
0.65\end{array}$ & & $\begin{array}{c}57.38 \pm \\
0.81\end{array}$ & & $\begin{array}{c}28.32 \pm \\
0.78\end{array}$ & $\begin{array}{c}30.14 \pm \\
0.42\end{array}$ & $\begin{array}{c}39.29 \pm \\
0.68^{\mathrm{e}} \\
\end{array}$ \\
\hline 2 & $\begin{array}{l}60.52 \pm \\
1.06\end{array}$ & $\begin{array}{c}45.18 \pm \\
0.83\end{array}$ & $\begin{array}{c}33.10 \pm \\
0.81\end{array}$ & $\begin{array}{c}33.94 \pm \\
0.71\end{array}$ & $\begin{aligned} 43.19 \pm \\
0.80^{\mathrm{d}}\end{aligned}$ & $\begin{array}{l}62.12 \pm \\
0.94\end{array}$ & $\begin{array}{c}49.48 \pm \\
0.84\end{array}$ & $\begin{array}{c}34.41 \pm \\
0.34\end{array}$ & $\begin{array}{c}36.15 \pm \\
0.48\end{array}$ & $\begin{aligned} 45.54 \pm \\
0.83^{\mathrm{d}}\end{aligned}$ \\
\hline 3 & $\begin{array}{l}74.31 \pm \\
1.12\end{array}$ & $\begin{array}{l}52.26 \pm \\
0.85\end{array}$ & $\begin{array}{l}42.36 \pm \\
0.84\end{array}$ & $\begin{array}{c}45.46 \pm \\
0.92\end{array}$ & $\begin{array}{c}53.60 \pm \\
1.06^{\mathrm{c}}\end{array}$ & $\begin{array}{c}75.27 \pm \\
1.11\end{array}$ & $\begin{array}{c}60.17 \pm \\
0.96\end{array}$ & $\begin{array}{c}45.25 \pm \\
0.82\end{array}$ & $\begin{array}{c}47.14 \pm \\
0.80\end{array}$ & $\begin{array}{c}56.96 \pm \\
0.92^{\mathrm{c}}\end{array}$ \\
\hline 4 & $\begin{array}{c}83.48 \pm \\
1.14\end{array}$ & $\begin{array}{c}63.40 \pm \\
0.92\end{array}$ & $\begin{array}{c}54.72 \pm \\
0.91\end{array}$ & $\begin{array}{c}54.78 \pm \\
0.98\end{array}$ & $\begin{array}{c}64.10 \pm \\
1.23^{\mathrm{b}}\end{array}$ & $\begin{array}{c}89.13 \pm \\
1.53 \\
\end{array}$ & $\begin{array}{c}68.35 \pm \\
1.13\end{array}$ & $\begin{array}{c}54.11 \pm \\
0.93\end{array}$ & $\begin{array}{c}55.43 \pm \\
1.16\end{array}$ & \begin{tabular}{|c|}
$66.76 \pm$ \\
$1.04^{\mathrm{b}}$ \\
\end{tabular} \\
\hline 5 & $\begin{array}{c}100.15 \pm \\
1.82\end{array}$ & $\begin{array}{c}76.15 \pm \\
1.74\end{array}$ & $\begin{array}{c}65.11 \pm \\
1.54\end{array}$ & $\begin{array}{c}66.80 \pm \\
1.63\end{array}$ & $\begin{array}{c}77.05 \pm \\
1.38^{\mathrm{a}}\end{array}$ & $\begin{array}{c}104.16 \pm \\
1.72\end{array}$ & $\begin{array}{c}77.16 \pm \\
1.52\end{array}$ & $\begin{array}{c}65.18 \pm \\
1.12\end{array}$ & $\begin{array}{c}66.17 \pm \\
1.18\end{array}$ & \begin{tabular}{|c|}
$78.17 \pm$ \\
$1.23^{\mathrm{a}}$
\end{tabular} \\
\hline Mean & $\begin{array}{c}70.49 \pm \\
1.13^{\mathrm{A}}\end{array}$ & $\begin{array}{c}52.66 \pm \\
1.64^{\mathrm{B}}\end{array}$ & $\begin{array}{c}41.69 \pm \\
1.11^{\mathrm{C}}\end{array}$ & $\begin{array}{c}42.76 \pm \\
1.04^{\mathrm{C}}\end{array}$ & $51.90^{\mathrm{A}}$ & $\begin{array}{c}74.05 \pm \\
1.17^{\mathrm{A}}\end{array}$ & $\begin{array}{c}56.10 \pm \\
1.14^{\mathrm{B}}\end{array}$ & $\begin{array}{c}42.40 \pm \\
0.84^{\mathrm{C}}\end{array}$ & $\begin{array}{c}44.19 \pm \\
0.93^{\mathrm{C}}\end{array}$ & $54.18^{\mathrm{A}}$ \\
\hline
\end{tabular}

A,B,C : Means with the different superscripts in the same row, differ significantly $(\mathrm{P}<0.05)$.

a,b,c,d,e : Means with the different superscripts in the same column, differ significantly $(\mathrm{P}<0.05)$.

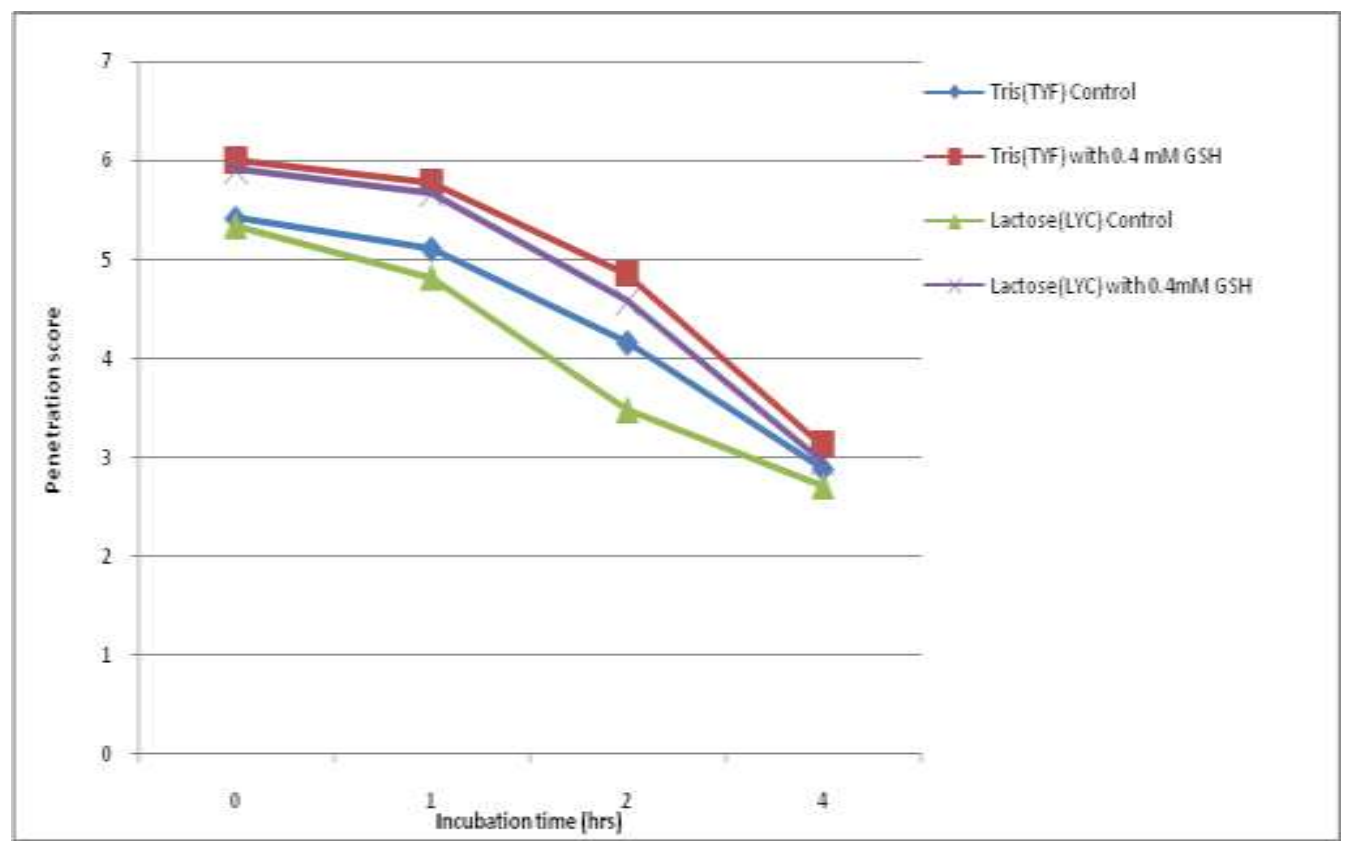

$\overline{\text { Kafrelsheikh Vet. Med. J. Vol. } 17 \text { No. } 1 \text { (2019) }}$ 
Fig. (1): Penetration score values of the extended camel spermatozoa with the different extenders into she-camel cervical mucus, during incubation at $37^{\circ} \mathrm{C}$ for up to 4 hour.

In conclusion, the extended camel semen with Tris-yolk-fructose (TYF) or Lactose-yolk-citrate (LYC)extender showed better sperm motility, longevity of the dromedary camelspermatozoa during storage at $5^{\circ} \mathrm{C}$ for up to 5 days. It can be recommend to extension of camel semen with TYF or LYC extender supplemented with $0.4 \mathrm{mM}$ GSH for maintaining of survival rate of spermatozoa, as well as, sperm motility, maintaining enzymatic activities and sperm penetration into she-camel cervical mucus for artificial insemination programs to enhancement of fertilizing ability of the dromedary camel spermatozoa.

\section{REFERENCES}

- Ahmed, I.A. (2008). Effect of adding ascorbic acid to semen of Egyptian buffalo bulls.M.Sc. Thesis, Fac. Agric., Mansoura Univ., Mansoura, Egypt.

- Aitken, R.J., Best, F., Richardson, D.W., Schats, R. and Simm, G. (1983). Influence of caffeine on movement characteristics, fertilizing capacity and ability to penetrate cervical mucus of human spermatozoa. J. Reprod. Fert.,67(1): 19-27.

- Arafat, M. H.,(2015). Studies on storage of dromedary camel semen. Ph. D. Thesis, Fac. Agric., Al-Azhar University, Cairo, Egypt. 
- Banerjee, G. (1988). Feeds and Principles of Animal Nutrition. Oxford and IBH Publishing, New Delhi, India.

- Bartlett, F.D., Jr. and Van Demark, N.L.(1962). Effect of diluent composition on survival and fertility of bovine spermatozoa stored in carbonated diluents. J. Dairy Sci., 45(3): 360-367.

- Bravo, P.W., Skidmore, J.A. and Zhao, X.X. (2000). Reproductive aspects and storage of semen in Camelidae.Anim. Reprod. Sci., 62 (1-3): 173-193.

- Duncan,D.B., (1955). Multiple range and multiple F tests. Biometrics, 11 (1): 1-42.

- Eskin, B.A., Azarbal, S., Sepic, R. and Slate, W.G. (1973). In Vitro responses of the spermatozoa-cervical mucus system treated with Prostaglandin (F2 $\alpha$ ). Obstetrics \& Gynecology, 41(3): 436-439.

- Foote, R.H., (1978). Extenders and extension of unfrozen semen. In: G.W. Salisbury, N.L. Van Demark and J.R. Lodge (Editors), Physiology of Reproduction-Artificial Insemination of Cattle. W. H. Freeman and Company, SF, USA, pp. 442-493.

- Hackett, A.J. and Macpherson, J.W. (1965). Some staining procedures for spermatozoa. A review. Canadian Vet. J., 6 (3): 55-62.

- Hanson, F.W., Overstreet, J.W. and Katz, D.F. (1982). A study of the relationship of motile sperm numbers in cervical mucus 48 hours after artificial insemination with subsequent fertility. American J. Obstet. Gynecol., 143: 85-90. 
- Khan, A.A. (1971). Sexual behaviour of the male camel (Camelusdromedarius) and some studies on semen. M. Sc. Thesis, University of Udaipur, Udaipur, Rajasthan, India.

- Kumar, S. and Das, G. (2005). Frozen sperm quality with reference to reactive oxygen species: A review. Indian J. Anim. Sci., 75(7): 874-884.

- Lewis, S.E., Sterling, E.S., Young, I.S. and Thompson, W. (1997). Comparison of individual antioxidants of sperm and seminal plasma in fertile and infertile men.Fertil.Steril.,67(1): 142-7.

- Matter, M. A. S. (2018). Reproductive and physiological studies on the male dromedary camels during breeding and non-breeding seasons under Egyptian condition.Msc Thesis, Animal Production Department, Faculty of Agriculture, Al-Azhar University, Cairo, Egypt.

- Maxwell, W. and Salamon, S. (1993). Liquid storage of ram semen: a review. Reprod. Fertil.Develop.,5(6): 613-638.

- Maiada, W. A. Allam (2011). Reproductive and physiological performance of male dromedary camels during breeding and non-breeding seasons. M.Sc. Thesis, Fac., Agric. Ain Shams Univ., Cairo, Egypt.

- Mosaferi, S., Niasari-Naslaji, A., Abarghani, A., Gharahdaghi, A.A. and Gerami, A. (2005). Biophysical and biochemical characteristics of bactrian camel semen collected by artificial vagina. Theriogenology, 63(1): 92-101. 
- Murase, T., Okuda, K. and Sato, K., (1990). Assessment of bull fertility using a mucus penetration test and a human chorionic gonadotrophin stimulation test. Theriogenology, 34 (5): 801-812.

- Musa, B., Sieme, H., Merkt, H. and Hago, B.(1992). Artificial insemination in dromedary camels. Proc. $1^{\text {st }}$ International Camel Conference. R\&W Publications, Newmarket, Suffolk, UK, pp. 179-82.

- Rasul, Z., Anzar, M., Jalali, S. and Ahmad, N. (2000). Effect of buffering systems on post-thaw motion characteristics, plasma membrane integrity, and acrosome morphology of buffalo spermatozoa.Anim. Reprod. Sci., 59(1-2): 31-41.

- Reitman, S. and Frankel, S. (1957). A colorimetric method for determination of serum glutamic oxaloacetic and glutamic pyruvic transaminases.American J. Clin. Path., 28: 56-63.

- $\boldsymbol{S A S}$ (2006). SAS Users Guide, Statistical Analysis System Institute. Inc. Editors, Cary, Nc.

- Tibary, A. and Anouassi, A. (1997). Theriogenology in Camelidae. Anatomy, Physiology. Pathology and Artificaial Breeding. First Edition, Abu Dhabi, U. A. E.

- Vyas, S., Goswami, P., Rai, A. and Khanna, N. (1998). Use of Tris and lactose extenders in preservation of camel semen at refrigerated temperature. Indian Vet.J.,75(9): 810-812.

- Watson, P.F. (1975). Use of a Giemsa stain to detect changes in acrosomes of frozen ram spermatozoa. Vet. Rec., 97(1): 12-15. 
- Zeidan, A.E.B. (1994). New aspects in freezing cattle semen.Ph.D. Thesis, Fac. Agric., Zagazig Univ., Zagazig, Egypt.

- Zeidan, A.E.B. (2002). Semen quality, enzymatic activities and penetrating ability of spermatozoa into she-camel cervical mucus as affected by caffeine addition. J. Camel Pract. Res., 9(2): 153-161.

- Zeidan, A.E.B., Abou-Aiana, R.M.,Ahmadi, E.A.A.,Abd El-aziz, N.A., Sayah, M.S., Amar, A.H. and Abd El-Salaam, A.M. (2008).

Viability and enzymatic leakage of the cooled camel spermatozoa in relation to different extenders. American-Eurasian J. Agric. Environ. Sci., 4: 142-149.

- Zeidan, A.E.B., El-Sharabassy, A.M., Dowidar, Y.A., Ashour, A.M., Abd El-Salaam and M.H. Arafat (2014). Impact of different extenders on semen quality and enzymatic activities of the male dromedary camel during storage at $5^{\circ} \mathrm{C}$ for up to 4 days.Egypt. J. Basic. Appl. Physiol., 14(2):329-348(201

تأثثير إضافة الجلوتاثيون للمخف على جودة السائل المنوي المبرد للجمال

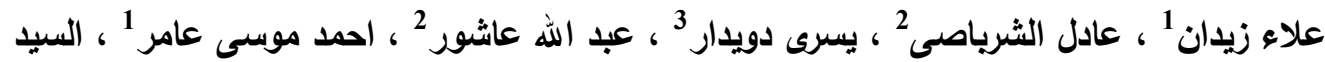

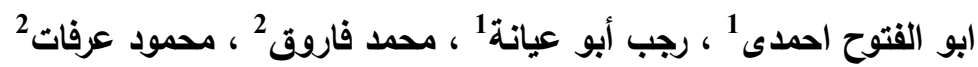

1'معهة بحوث الإتتاج الحيواني - مركز البحوث الزراعية- الدقي- الجيزة - مصر .

2 قسم الإنتاج الحيواني - كلية الزراعة - جامعة الأزهر - القاهرة - مصر .

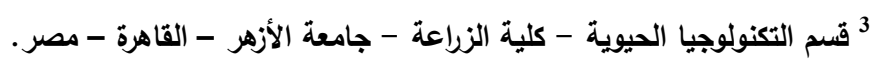

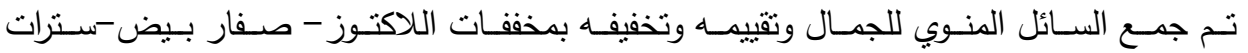

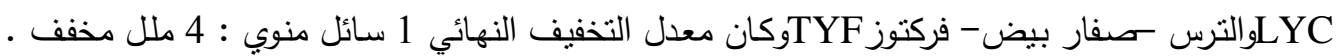

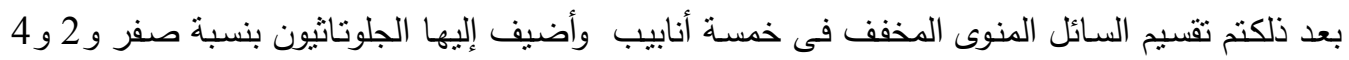

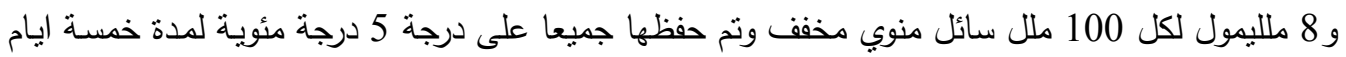


وبعد كل فترة تم تقدير كلا من النسبة المئوية لحيوية الحيوانات المنوية والحيوانات المنوية الميتة والحيوانات

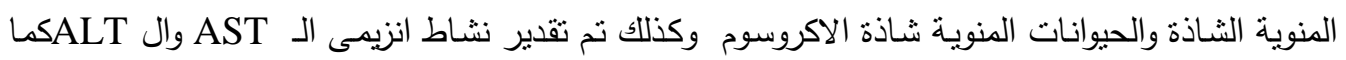

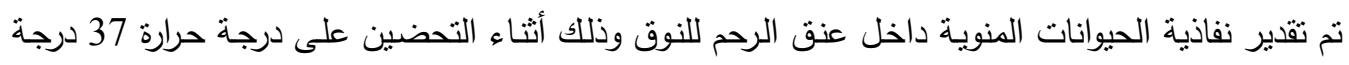

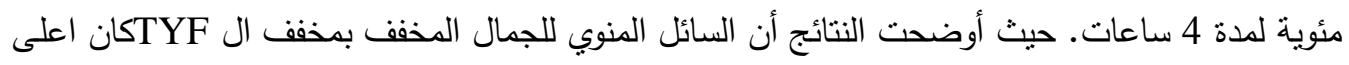
بدرجة معنوية (P<0.05) في النسبة المئوية لحيوية الحيوانات المنوية بينما كانت النسبة المئوية للحيوانات المنوية الميتة والحيوانات المنوية الثـاذة والحيوانات المنوية شاذة الاكروسوم اقل بدرجة معنوية(P<0.05) وكذلك نسبة انزيمات الـ AST وال ALT فى الوسط الخلوي وذلك أثناء الحفظ على درجة حرارة درجة

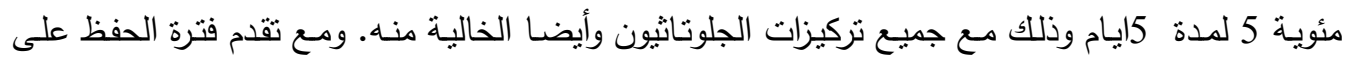

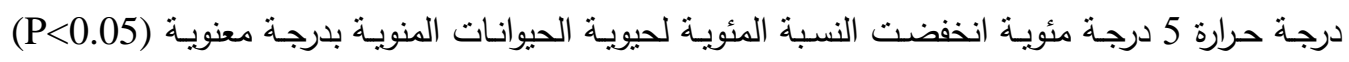

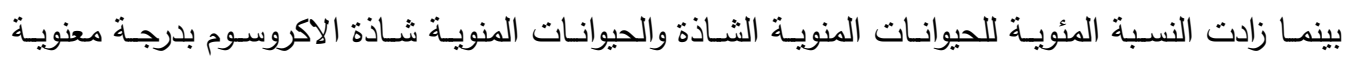
و وكنلك ازداد نشاط انزيمى الـ ALT وال ALT في الوسط الخلوي فى السائل الدنوي المخفف

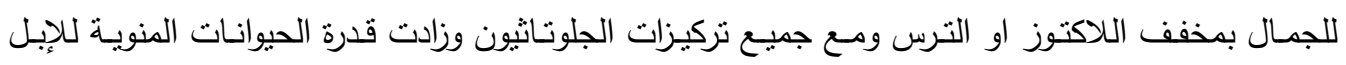

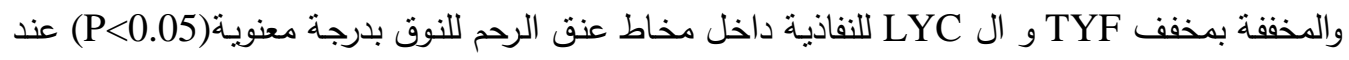

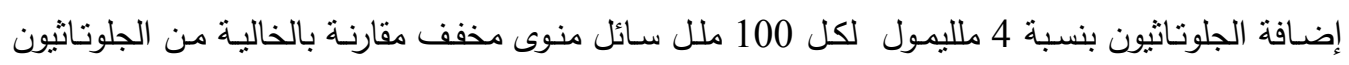

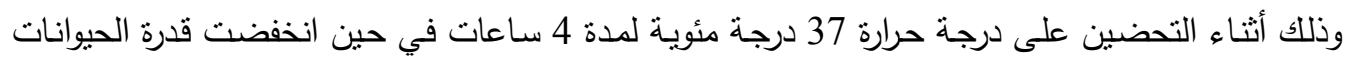
المنوية للإبل على اختراق مخاط عنق الرحم للنوق معنويا (P<0.05) بزيادة وقت التحضين. 